\title{
Double outlet left ventricle: diagnosis with magnetic resonance imaging
}

\author{
Sidney A Rebergen, Gerard L Guit, Albert de Roos
}

\begin{abstract}
A complex congenital cardiac malformation in a female patient was evaluated several times by angiocardiography and echocardiography in childhood but a definite diagnosis was not established. Segmental analysis of the heart and the great vessels by magnetic resonance imaging when the patient was 34, however, showed a double outlet left ventricle in which the aorta was situated anterior to and to the left of the pulmonary trunk and an associated subaortic ventricular septal defect with pulmonary valve stenosis.

This is the first time that this extremely rare cardiac malformation has been diagnosed by magnetic resonance imaging.
\end{abstract}

Double outlet left ventricle is a rare (incidence less than 1 in $200000^{1}$ ) congenital cardiac malformation in which the aorta and the pulmonary trunk both arise entirely or predominantly above the morphologically left ventricle. Eighteen cases of the type described in this paper have been reported. ${ }^{2}$

Magnetic resonance imaging is a valuable, non-invasive tool for the visualisation of the anatomy of the heart, especially when complex cardiac malformations are suspected. ${ }^{3}$ It can also be used to perform segmental analysis ${ }^{4}$ to define atrial situs, atrioventricular connections, ventricular morphology, ventriculoarterial connections, the position of the great arteries, and associated defects. We describe the use of magnetic resonance imaging in a case of double outlet left ventricle in which a definite diagnosis was never established despite extensive echocardiographic and angiocardiographic examination.

\section{Case report}

This female patient presented with asphyxia and frequent attacks of mild cyanosis shortly after birth and was examined by angiocardiography at the age of 11 years (we have no information on earlier examinations). The diagnosis at the time was a double outlet right ventricle of the Taussig-Bing type associated with a ventricular septal defect.

At the age of 15 years she complained of fatigue during moderate exercise. Physical examination showed moderate cyanosis, cardiomegaly, a pansystolic murmur $3 / 6$ at the apex, and an ejection type murmur $5 / 6$ over the second left intercostal space. The electrocardiogram showed right axis deviation and a right bundle branch block pattern. The chest $x$ ray showed an enlarged heart, a narrow vascular pedicle, and pulmonary plethora. A ventricular septal defect with right to left shunting and pulmonary stenosis was suspected. She was recatheterised and the suspected findings were confirmed. The origin of the aorta was shown to be anterior and to the left of the origin of the pulmonary trunk. Oxygen saturation was higher in the pulmonary artery $(84 \%)$ than in the aorta $(77 \%)$. Surgical correction was not advised at the time because the symptoms were mild.

Echocardiography when she was 32 reconfirmed the results of angiocardiography, but a definite diagnosis could not be established. At the age of 34 , cyanosis had slightly increased and the patient was referred to our hospital for magnetic resonance imaging of the heart and great vessels. Spin echo acquisitions were performed in the three orthogonal planes with a $1.5 \mathrm{~T}$ imager (Philips Gyroscan). The study was continued with a sagittally oriented gradient (cine) echo acquisition in the plane through the ventricular septal defect to visualise shunt flow and left ventricular outflow. Segmental analysis was used to identify atrial situs, ventricular morphology, atrioventricular connections, ventriculoarterial connections, position of the great arteries, and associated defects.

SITUS

The bronchial anatomy seen on conventional

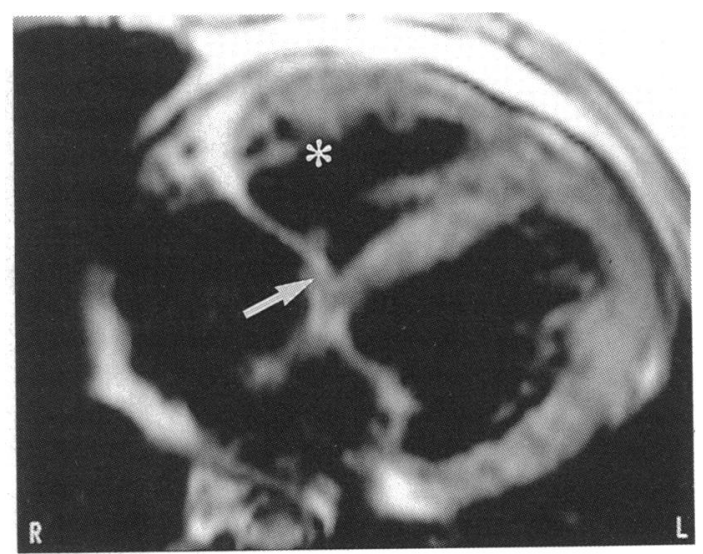

Figure 1 Magnetic resonance image of an axial slice a midventricular level shows the slightly more apical attachment of the tricuspid valve to the septum (arrow) and the coarser trabeculation of the anterior ventricle and the coarser trabeculation of the anterior ventricle
(asterisk), indicating a morphologically right ventricle. The muscular infundibulum was identified in a more cephalad section. 


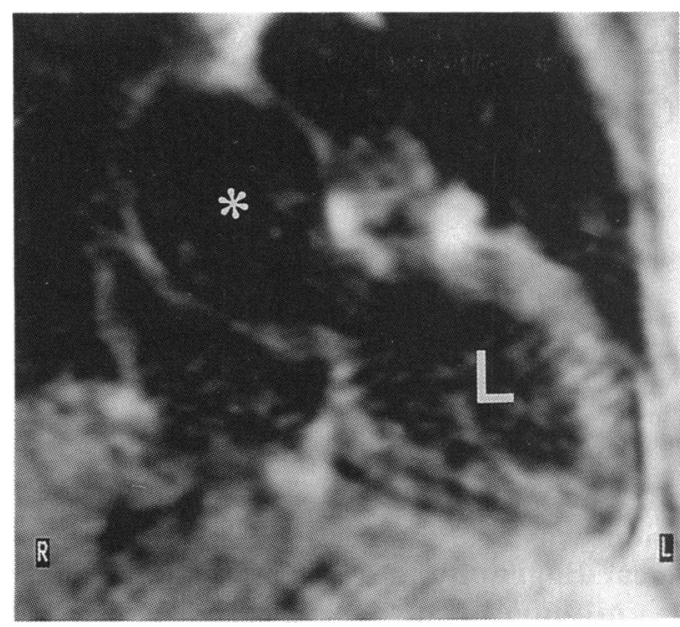

Figure 2 Magnetic resonance image of a coronal slice through the posterior morphologically left ventricle $(L)$, showing the connection with the severely dilatated pulmonary trunk (asterisk).

radiography indicated situs solitus of the atria. This was confirmed by identification of the atrial appendages and the location of the inferior vena cava, abdominal aorta, liver and stomach on a coronal magnetic resonance imaging series. Both venae cavae drained normally into the right atrium.

\section{ATRIOVENTRICULAR CONNECTIONS}

Axial slices showed that the anteriorly situated ventricle was the morphologically right ventricle, in view of the thick muscular outflow tract, the trabecular pattern, and the more apical septal slip attachment of the tricuspid valve to the septum compared with the mitral valve. Moreover, there were two atria, each draining into their own ventricle (fig 1). The total picture was one of biventricular concordant atrioventricular connections.

\section{VENTRICULOARTERIAL CONNECTIONS}

The coronal slices clearly showed a dilated pulmonary trunk originating from the posterior (morphological left) ventricle (fig 2) The left sided aorta was connected with the infundibulum of the anterior ventricle, strad-

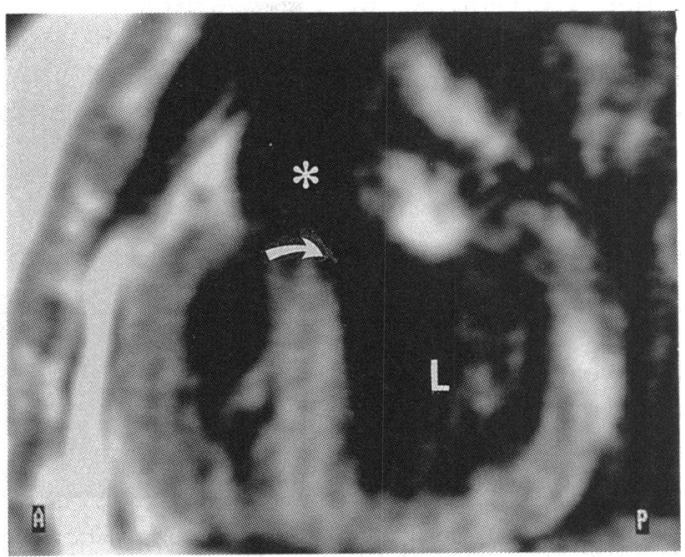

Figure 3 Magnetic resonance image of a sagittal slice in the plane of the ventricular septal defect (arrow) clearly showing the relation of the aorta (asterisk) to the defect, resulting in the posterior, morphologically left ventricle

(L) being the main source of aortic blood supply. dling the ventricular septum in such a way that most of the aorta arose above the left ventricle. This indicated that the patient had a double outlet left ventricle.

\section{POSITION OF THE GREAT ARTERIES}

The origin of the pulmonary trunk was located to the right, caudal, and posterior of the aortic origin-a situation which is often seen in congenitally corrected (discordant atrioventricular connections) transposition. A subaortic muscular infundibulum was identified together with pulmonary-mitral fibrous continuity.

\section{ASSOCIATED DEFECTS}

A defect of the atrial septum was found within the region of the oval fossa. ${ }^{56}$ The ventricular septal defect was clearly visualised in the sagittal plane (fig 3). The location was subaortic, resulting in the aorta being supplied mainly by the morphological left ventricle.

\section{FUNCTIONAL EVALUATION}

Cine magnetic resonance imaging, especially in the movie mode, showed diastolic right to left shunting and systolic flow from the left ventricle into the aorta.

Segmental analysis performed with magnetic resonance imaging indicated a diagnosis of double outlet left ventricle in which the origin of the aorta lay anterior and left from the origin of the pulmonary trunk together with severe dilatation of the pulmonary trunk (consistent with the pulmonary valve stenosis found at echocardiography), a subaortic ventricular septal defect with right to left shunting, and an atrial septal defect within the region of the oval fossa.

\section{Discussion}

Double outlet ventricles with biventricular arterioventricular connections account for about $1 \%$ of all cases of congenital heart disease and the left ventricle is affected in less than $5 \%$ of these cases. ${ }^{2}$ Over 100 cases of double outlet left ventricle have been reported since $1967 .{ }^{27}$ Before then this anomaly was regarded as being embryologically impossible. ${ }^{8}$ Until recently this complex malformation could be examined only by angiocardiography. ${ }^{9}$ In our patient surgical intervention was postponed because cyanosis was mild and the anatomical diagnosis was uncertain. Because of the patient's increasing fatigue and cyanosis magnetic resonance imaging was performed to elucidate the anatomy and haemodynamic function.

Surgical correction is often achieved by closing the ventricular septal defect, disconnecting the pulmonary trunk from the left ventricle, and re-establishing the connection between the right ventricle and pulmonary trunk through an external conduit. In some cases a Fontan-type correction may be preferred. Even intraventricular rerouting can be performed occasionally. ${ }^{9}$ The development of pulmonary arterial hypertension, however, may limit the surgical options. When a final 
diagnosis cannot be established with the conventional methods, magnetic resonance imaging can be of great value in the analysis of complex congenital malformations of the heart, as is shown in this case of a very rare cardiac malformation.

We thank Dr M El Gamal, Department of Cardiology, Catharina Hospital, Eindhoven, The Netherlands for referring the patient and Dr J Doornbos, Department of Diagnostic Radiology, University Hospital Leiden, The Netherlands for his technical support.

1 Wilkinson JL. Double outlet ventricle. In: Anderson RH, Macartney FJ, Shinebourne EA, Tynan M, eds. Paediatric cardiology, vol 2. Edinburgh: Churchill LivingPaediatric cardiology,
stone, 1987:889-911.

2 Van Praagh R, Weinberg PM, Srebro JP. Double outlet left ventricle. In: Adams FH, Emmanouilides GL, Riemenventricle. In: Adams FH, Emmanouilides GL, Riemen-
schneider TA, eds. Moss' heart disease in infants, children and adolescents. Baltimore: Williams and Wilkins, 1989: 461-73.

3 Kersting-Sommerhoff BA, Diethelm L, Stanger P, et al. Evaluation of complex congenital ventricular anomalies with magnetic resonance imaging. Am Heart J 1990; 120:133-42.

4 Guit GL, Bluemm R, Rohmer J, et al. Levotransposition of the aorta: identification of segmental cardiac anatomy using MR imaging. Radiology 1986;161:673-9.

5 Dinsmore RE, Wismer GL, Guyer D, et al. Magnetic resonance imaging of the interatrial septum and atria septal defects. $A J R$ 1985;145:697-703.

6 Diethelm L, Déry R, Lipton MJ, Higgins CB. Atrial-level shunts: sensitivity and specificity of $M R$ in diagnosis. Radiology 1987;162:181-6.

7 Otero Coto E, Quero Jimenez M, Castaneda AR, Rufilanchas JJ, Deverall PB. Double outlet from chambers of left ventricular morphology. Br Heart J 1979;42:15-21.

8 Van Mierop LHS, Wiglesworth FW. Pathogenesis of transposition complexes. II. Anomalies due to faulty transfer of the posterior great artery. Am J Cardiol 1963;12:226-32.

9 Brandt PWT, Calder AL, Barrat-Boyes BG, Neutze JM. Double outlet left ventricle. Morphology, cineangiocardiographic diagnosis and surgical treatment. $A m ~ J$ Cardiol 1976;38:879-909. 